\title{
AN AUTOMATED SOFTWARE FRAMEWORK FOR EVALUATION AND IMPROVEMENT OF ABSOLUTE GEOMETRIC LOCATION ACCURACY OF MULTISPECTRAL REMOTE SENSING SATELLITE IMAGERY
}

\author{
Yatharath Bhateja ${ }^{1, *}$, Indranil Misra ${ }^{1}$, S. Manthira Moorthi ${ }^{1}$, Debajyoti Dhar ${ }^{1}$ \\ ${ }^{1}$ Optical Data Processing Division, Signal and Image Processing Group \\ Space Applications Centre (ISRO), Ahmedabad 380015, India \\ \{ybhateja, indranil, smmoorthi, deb\}@sac.isro.gov.in
}

\section{Commission V, WG -V/8: PROMOTION OF OPEN SOURCE ON GEOSPATIAL TECHNOLOGY}

\author{
KEY WORDS: Geometric Location Accuracy, GCP, Feature Point, GIS, Remote Sensing, Data Product.
}

\begin{abstract}
:
Geometric accuracy is an important parameter for quality assessment of a data product and is vital for certain applications aiming on improving and bringing precision in data products. Automatic geometric accuracy evaluation of the satellite image is attempted by matching a known, surveyed location typically a ground control point (GCP) calibrated using a differential global positioning system (DGPS), verified using Google Maps, to the corresponding identifiable feature in an image product. The requirement for this development is to address the non - uniformity in the available data products in terms of coordinates reference system, resolution and available bands, which the software overcomes successfully by benefiting from the classes and functions available in openly available GIS libraries. RMSE of 0.8 pixels is found in analysis for the chosen data. Further, an algorithm is worked up to rectify the image for this geometric shift.
\end{abstract}

\section{INTRODUCTION}

There has been an increasing demand in finding the absolute geometric location accuracy, to improve on exactness and efficiency of generated data products obtained from different sensors of multiple satellites with varied resolutions. This process is part of a higher program of research projects in remote sensing domain which are focused on improving and bringing precision in data products, thereby helping the users to generate an absolute reference of the mapped terrain, by means of multisource and multi-temporal geospatial data. In this sense, finding the absolute geometric accuracy of the generated data product is of utmost importance for remote sensing studies.

Absolute geolocation accuracy is a measure of the location of an object, as it appears in a data product, by comparing it to its true positioning on the Earth (Aguilar, 2012; Turner, 2012). Geolocation accuracy is driven by the sensors and models used in the imagery collection system and by terrain displacement when the image pixels are projected to a surface on the Earth. Geometric accuracy is ascertained by matching a known, surveyed location typically a ground control point (GCP) to the corresponding photo-identifiable feature in an image product (Harwin et.al., 2012; Fujisada et.al., 2005).

For every individual control point, the geolocation error is computed by calculating the difference between the

\footnotetext{
* Corresponding author
}

discerned location in the product and the known, mapped out location. This in itself is a challenging and daunting task, as the software had to accommodate the variations in the available satellite images. To cater to this need, the software makes use of openly available (LGPL) (Steiniger et.al., 2009; Li et.al., 2009) Java library GeoTools (Turton, 2008) and Geospatial Abstraction Library (GDAL) (Warmerdam, 2008), which provides standard compliant methods for the manipulation of geospatial data to implement Geographic Information Systems. This is a part of the FOSS4G (Free and Open Source Software for Geospatial) initiative (Steiniger et.al., 2009). Java Topology Suite(JTS) was exploited by GeoTools to provide an integrated Geometry Support. GeoTools even provides us with methods for supporting different coordinate reference system as well as transforming from one system to another thereby helping us to analyse data in terms of spatial and non-spatial attributes.

Moreover, the task of image registration as well as coregistration being used up till now (also being used currently), provided geometrical accuracy w.r.t. reference datasets and not an absolute reference. To this end, Image registration has been performed using GCP sites calibrated using DGPS. In addition to this, the proposed software minimises human intervention by automatically ingesting the GCPs in the specified format, thereby reducing the error figures significantly (Chen et.al., 2012). The software presented in this paper is a novel solution for evaluating the absolute geometric location accuracy of remote sensing satellite images. 


\section{SOFTWARE DETAILS}

Today there are a number of software packages available in the market for working with remote sensing satellites data for geometric assessment. This software aims at finding the geometric accuracy of the available multispectral and multitemporal images with varying resolutions w.r.t. GCP sites. Java platform is used for software development to accomplish the set objectives. The primary target of this software was to handle the problems arising from the differences in the multispectral images. The software provides a platform for standard compliant methods to manipulate geospatial data thereby implementing Geographic Information Systems in the form of GeoAPI (Jena and Roehrig, 2007). This GeoAPI is a set of Java interfaces providing Application Programming Interfaces (APIs) and following OGC/ISO standards to allow better interoperability among the different java-based geographic projects and low level libraries. The software offers the users a simplified environment where in they can calculate the absolute geolocation accuracy of the data products in minimal time and with very little intervention.

The software makes use of MapContent and MapPane classes to display the data product image as a GridCoverageLayer. The GCP lying on the current scene are then added on the MapContent as separate Layers. Whenever the operator selects a particular GCP, all the other GCP layers get hidden, and the operator is prompted to identify the feature (in the GCP) on the full resolution view of the image, along with the automatically identified location. As soon as the operator successfully identifies and confirms the feature, the software automatically computes the difference in Latitude and Longitude, the RMSE displacement, tabulates the results, and also saves them in a report file. Since the remote sensing data being used is multispectral, the software caters to this requirement by giving the operator option to view the bands separately, or combine them together to get a RGB display.

\section{Salient features of the software -}

- Conversion from one coordinates reference system to another.

- Contrast Enhancement of images to easily identify the features.

- $\quad$ Loading all the available GCPs inside the data product.

- Automatically calculate the individual difference and the RMSE.

- View different bands of the scene or selective bands together.

\section{STEPS INVOLVED}

3.1 Ingestion: This step reads the image meta information. In case of a multispectral data, only one of the bands is shown initially with an option to select other bands or see a combined RGB display. The software also reads a metadata file to read other information about the image.

3.2 Target coordinate reference system: The software shows the current coordinate reference system, and provides users with an option to convert to different (target) coordinate reference system (for the purpose of this report, EPSG:4326) (Regina et.al., 2015).

3.3 GCP collection: This step collects the information (latitude and longitude) of all the available GCPs and then precisely marks all the points that lie within the data product. The software makes uses of a specified format to read the GCP information that needs to be provided along with GCP Image.

GCP_ID; GCP_LOCATION_NAME; GCP_LATITUDE; GCP_LONGITUDE; GCP_DATE; TERRAIN; ZONE; AREA; GCP_IMAGE_WIDTH; GCP_IMAGE_HEIGHT

3.4 Feature Identification: In addition to automatic feature extraction of the calibrated GCP using image to image correlation, the software developed allows human intervention to manually identify/confirm the feature from the GCP chip.

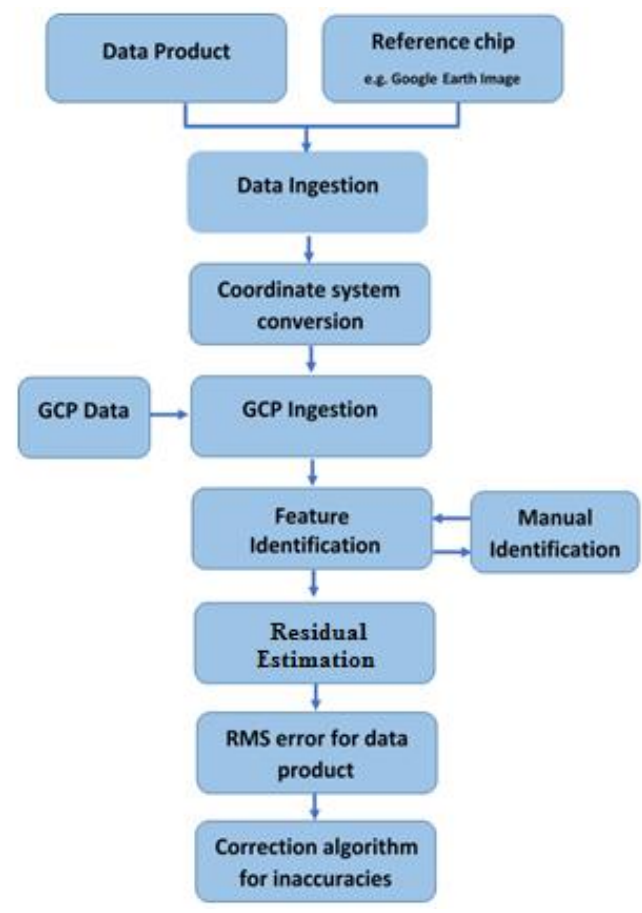

Figure 1. Software Workflow

3.5 Result/Output: This phase is once again an automatic step, after the operator has successfully identified the feature point (for all the GCPs), the software computes the difference in latitude and longitude of the marked and actual feature and tabulates the result in a report for future reference. Also it provides 
the user with mean error across track and also along track, along with the RMSE.

3.6 Correction: As a final correction step, the image is rectified to absorb the residual error computed in the previous step and improve the absolute geometric accuracy of the image.

For clearer understanding, the above mentioned steps have been depicted in the form of a flow chart in Figure1 outlining all the important steps, and the order of these steps.

\section{DATA USED FOR EVALUATION AND RESULTS ACHIEVED}

For the present paper, data from RESOURCESAT - 2A mentioned in Table 1 have been used to test and verify the correctness of this software. RESOURCESAT-2A is a Remote Sensing satellite intended for resource monitoring. It is intended to continue the remote sensing data services to global users provided by RESOURCESAT-1 and RESOURCESAT-2

RESOURCESAT-2A carries three payloads which are similar to those of RESOURCESAT-1 and RESOURCESAT-2. First is a high resolution Linear Imaging Self Scanner (LISS-4) camera operating in three spectral bands in the Visible and Near Infrared Region (VNIR) with $5.8 \mathrm{~m}$ spatial resolution and steerable up to \pm 26 degrees across track to achieve a five-day revisit capability. The second payload is the medium resolution
LISS-3 camera operating in three-spectral bands in VNIR and one in Short Wave Infrared (SWIR) band with 23.5 $\mathrm{m}$ spatial resolution. The third payload is a coarse resolution Advanced Wide Field Sensor (AWiFS) camera operating in three spectral bands in VNIR and one band in SWIR with $56 \mathrm{~m}$ spatial resolution.

To evaluate the performance of the software, Resourcesat-2A LISS-4 FMX data is used for evaluation to find the accuracy of the data product mentioned in Table 1. The software also computes a root mean square error (RMSE) (Walker et.al., 2006; Hodgson et.al., 2004) using equation 1 , which in turn provided an indication to the absolute geometric location accuracy of the data products.

$\mathrm{RMSE}=\sqrt{\frac{1}{\mathrm{~N}}} \sum_{\mathrm{i}=1}^{\mathrm{N}}\left\|\mathrm{M}_{\mathrm{i}}-\widehat{\mathrm{M}}_{\mathrm{i}}\right\|^{2}$

Where $\mathrm{N}=$ Total number of matched GCP,

$\mathrm{M}_{\mathrm{i}}$ are the $(\mathrm{x}, \mathrm{y})$ coordinates of GCP,

$\widehat{M}_{i}$ are the $\left(\widehat{x}_{1}, \widehat{y}_{1}\right)$ coordinates of the feature identified in our product corresponding to the GCP.

The results achieved were tabulated by the software itself for the data products mentioned in Table 2, which are within acceptable limits.

The differences were first calculated individually across track and along track and then overall difference was computed along with RMSE and is depicted in Table 2. A data product with marked GCP and reference chip are shown in Figure 2 and Figure 3 respectively.

\begin{tabular}{|c|c|c|c|c|c|c|}
\hline S.No & $\begin{array}{c}\text { City used for } \\
\text { GCP }\end{array}$ & $\begin{array}{c}\text { Date of } \\
\text { acquisition }\end{array}$ & $\begin{array}{c}\text { Path/Row/Sub- } \\
\text { Scene }\end{array}$ & Tilt Angle & $\begin{array}{c}\text { Centre } \\
\text { Latitude }\end{array}$ & $\begin{array}{c}\text { Centre } \\
\text { Longitude }\end{array}$ \\
\hline 1 & Delhi & $09^{\text {th }}$ May 2017 & $96 / 51 / \mathrm{C}$ & -2.620 & 28.965257 & 77.110339 \\
\hline 2 & Hyderabad & $05^{\text {th }}$ May 2017 & $100 / 61 / \mathrm{A}$ & -2.659 & 17.067372 & 78.361046 \\
\hline 3 & Alwar & $10^{\text {th }}$ Apr 2017 & $95 / 52 / \mathrm{B}$ & 1.524 & 27.777537 & 75.736781 \\
\hline
\end{tabular}

Table 1: Data Products used for evaluation

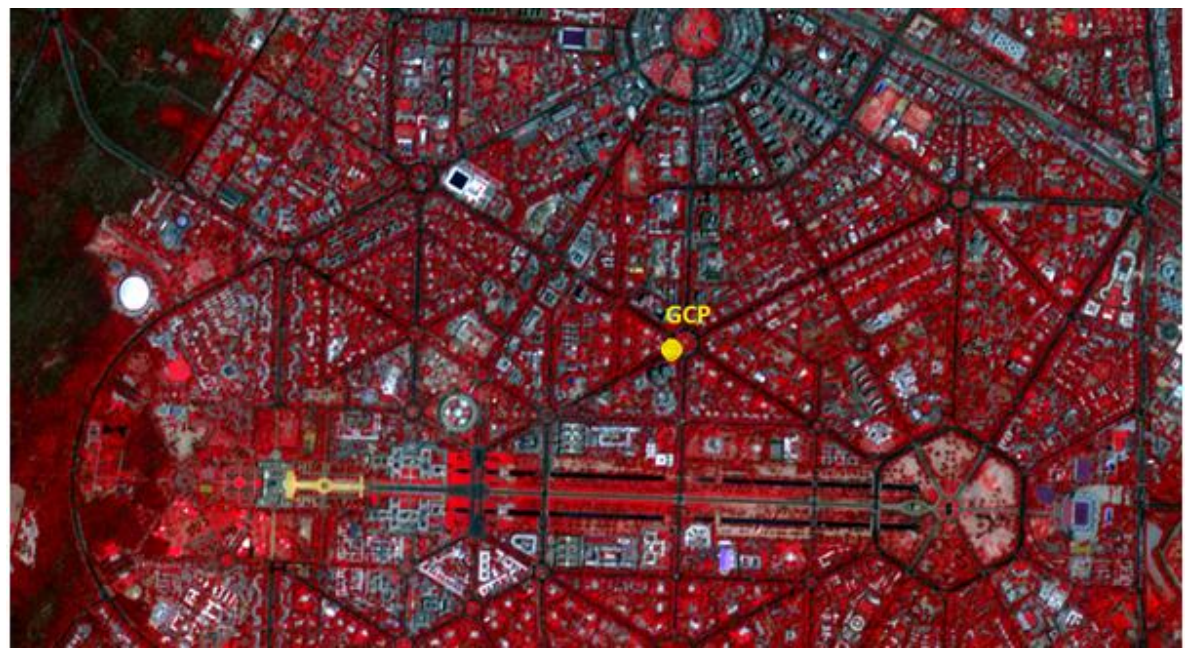

Figure 2. RS2A L4FMX Data Product 96/51/C. 


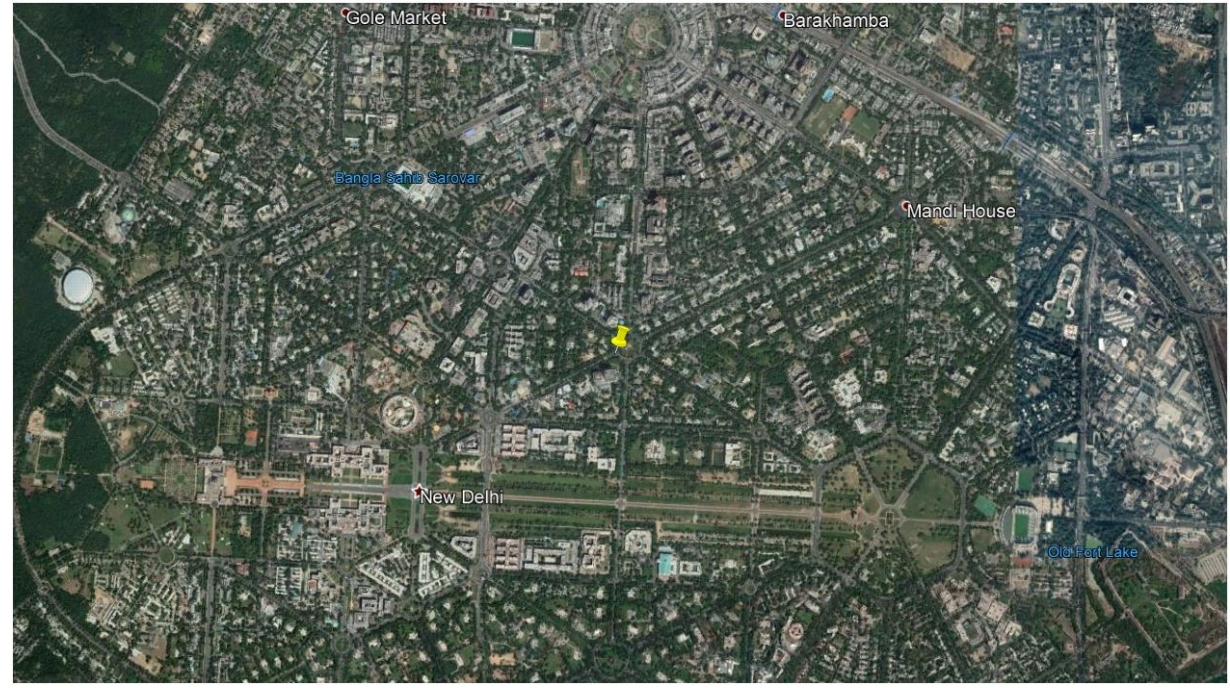

Figure 3. Corresponding Google Earth Reference Image

\begin{tabular}{|c|c|c|c|c|}
\hline GCP Location & $\begin{array}{l}\text { GCP } \\
\text { Point }\end{array}$ & $\begin{array}{c}\text { Difference (metres) } \\
\text { Along track }\end{array}$ & $\begin{array}{c}\text { Difference (metres) } \\
\text { Across track }\end{array}$ & $\begin{array}{c}\text { Difference (metres) } \\
\text { Total }\end{array}$ \\
\hline \multirow[t]{4}{*}{ DELHI } & 1. & 1.7738 & -1.8555 & 2.5670 \\
\hline & 2. & 2.0788 & -2.6733 & 3.3866 \\
\hline & 3. & 6.0853 & -3.2112 & 6.8804 \\
\hline & \multicolumn{4}{|c|}{ RMSE error for Delhi Data Product : $\mathbf{4 . 6 6 9 1 ~ m}$} \\
\hline \multirow[t]{4}{*}{ HYDERABAD } & 1. & -4.910949 & -0.071892 & 4.911475 \\
\hline & 2. & -3.544116 & 5.196272 & 6.289833 \\
\hline & 3. & 2.180772 & 5.793677 & 6.190514 \\
\hline & \multicolumn{4}{|c|}{ RMSE error for Hyderabad Data Product : 5.8311 m } \\
\hline \multirow[t]{6}{*}{ ALWAR } & 1. & 4.4020 & 1.5119 & 4.6544 \\
\hline & 2. & 4.4026 & 1.5164 & 4.6564 \\
\hline & 3. & 6.1581 & 1.4949 & 6.3369 \\
\hline & 4. & -2.6155 & 1.5934 & 3.0626 \\
\hline & 5. & 0.9331 & 4.6615 & 4.7539 \\
\hline & \multicolumn{4}{|c|}{ RMSE error for Alwar Data Product : $4.8058 \mathrm{~m}$} \\
\hline
\end{tabular}

Table 2: Observation Table for data products

The observations are listed in Table 2 and a graphical representation of the same is shown in Figure 4. To assert the correctness of the software and overall accuracy of the satellite images, we have tried to include data products from different areas with different terrains. It was observed the RMSE was consistent over terrains and was in a range of $2.5-7.0 \mathrm{~m}$. We found a RMSE of
$4.6691 \mathrm{~m}$ in Delhi data product, $5.8311 \mathrm{~m}$ in Hyderabad data product and $4.8058 \mathrm{~m}$ in Alwar data product, also shown in Figure 5.

For validation purpose we have also shown the RMSE calculated using control points from Cartosat -1 Reference tiles, as depicted in Table 3.

\begin{tabular}{|c|c|c|c|c|}
\hline GCP Location & $\begin{array}{c}\text { Number } \\
\text { of control } \\
\text { Points }\end{array}$ & $\begin{array}{c}\text { Average Difference } \\
\text { (metres) Along track }\end{array}$ & $\begin{array}{c}\text { Average Difference } \\
\text { (metres) Across track }\end{array}$ & $\begin{array}{c}\text { Average Difference } \\
\text { (metres) Total }\end{array}$ \\
\hline DELHI & 15 & 0.8754 & -4.8751 & 4.9530 \\
\hline HYDERABAD & 20 & -1.9872 & 0.8611 & 2.1657 \\
\hline ALWAR & 10 & 4.5654 & 0.4212 & 4.5847 \\
\hline
\end{tabular}

Table 3: RMSE calculation using ORTHO Reference tiles 


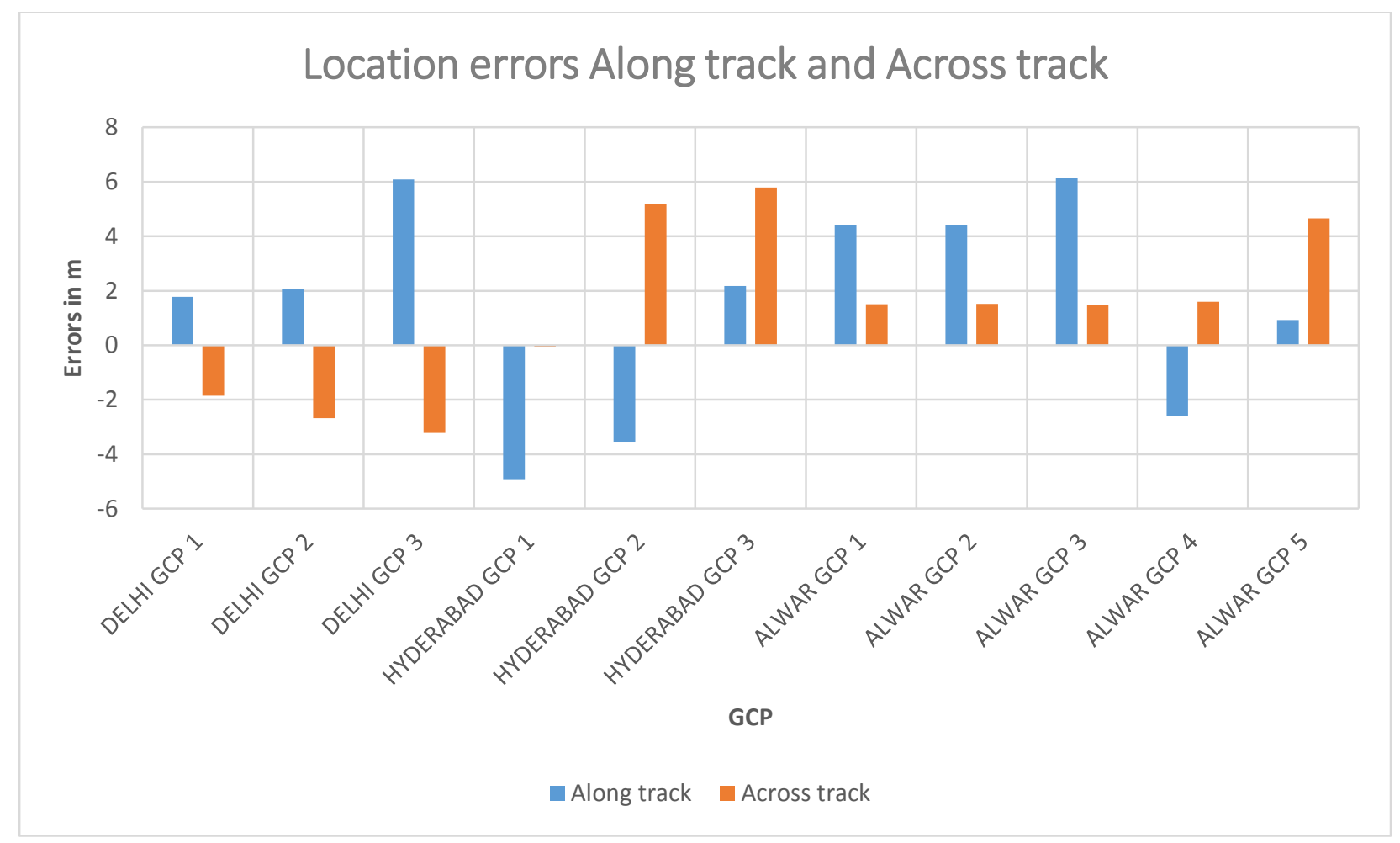

Figure 4. Graphical representation of Location Errors

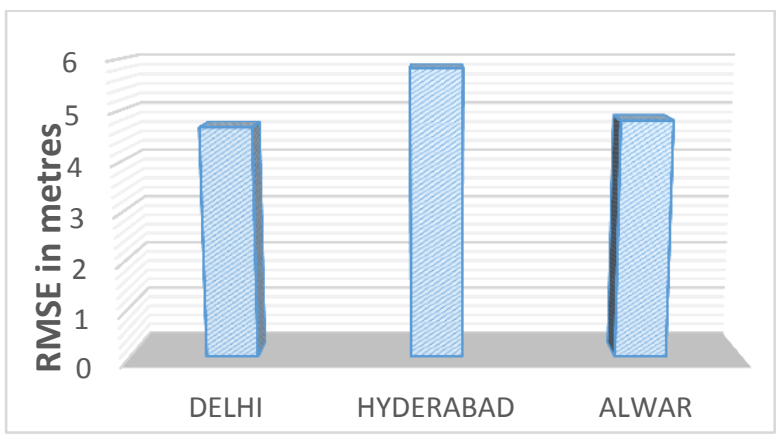

Figure 5. RMSE in metres

\section{CONCLUSION AND FUTURE SCOPE}

The proposed software is effectively able to determine the location accuracy for the evaluated data products, very quickly and also with minimal human intervention. LISS-4 MX datasets of GSD 5m were evaluated for subpixel accuracy in their geometric fidelity and a RMSE of 0.8 pixel is found in analysis. This software is an inhouse development project to automate the process of finding absolute location accuracy of multi-temporal data products. The data available is of varied sizes and resolutions and from different sensors. The software provides a uniform and standardized environment to take care of all the above mentioned problems, thereby making the process of finding geolocation accuracy easier. The ultimate purpose of this software is to help in generation of high resolution base map of India with an absolute geometric location accuracy which would vitally help in furtherance of other national level resource monitoring projects. Additional feature of the software enables correction of the residual error assessed. There are further plans to improve and bring in new efficient workflows.

\section{REFERENCES}

Aguilar, A.M., Aguilar, F.J., Saldaña, María del Mar, Fernández, I., 2012. Geopositioning Accuracy Assessment of GeoEye-1 Panchromatic and Multispectral Imagery. Photogrammetric Engineering and Remote Sensing. 78, 247-257.

Chen, Q.H., Liu X.G., Gao, W., Liu, T.L., 2009. An Automatic Ground Control Point Matching Based on GCP Chip Database for Remote Sensing Images. ICIASP, 2009 pp 13-17.

Fujisada, H., Bailey, G.B., Kelly, G.G., Hara, S., Abrams, M.J., 2015. ASTER DEM performance, IEEE Trans. Geosci. Remote Sens., vol. 43, no. 12, pp. 27072714.

Hodgson, M., Bresnahan, P., 2004. Accuracy of airborne lidar-derived elevation: Empirical assessment and error budget. Photogramm. Eng. Remote Sensing, 70, 331339. 
Jena, S., Roehrig, J., 2007. A Java Implementation of the OpenGISTM Feature Geometry Abstract Specification (ISO 19107 Spatial Schema).

Li X., Di, L., Han, W., Zhao P., Dadi, U., 2009. Sharing and Reuse of Service-based Geospatial Processing through a Web Processing Service. $17^{\text {th }}$ International Conference on Geoinformatics, pp 1-5.

Obe, R.O., Hsu, L.S., 1989. PostGIS in Action, Manning Publications Co., Greenwich, CT.

Steiniger, S., Bocher, E., 2009. An Overview on Current Free and Open Source Desktop GIS Developments, International Journal of Geographical Information Science, 1345-1370.

Steve, H., Lucieer, A., 2012. Assessing the Accuracy of Georeferenced Point Clouds Produced via Multi-View Stereopsis from Unmanned Aerial Vehicle (UAV) Imagery, Journal of Remote Sensing, Vol 4, pp. 15731599.

Turner, D., Lucieer, A., Watson, C., 2012. An Automated Technique for Generating Georectified Mosaics from Ultra-High Resolution Unmanned Aerial Vehicle (UAV) Imagery, Based on Structure from Motion (SfM) Point Clouds, Journal of Remote Sensing, Vol 4, pp. 1392-1410.

Turton I., 2008. Geo Tools. In: Hall G.B., Leahy M.G. (eds) Open Source Approaches in Spatial Data Handling. Advances in Geographic Information Science, vol 2. Springer, Berlin.

Walker, J.P., Willgoose, G.R., 2006. A comparative study of australian cartometric and photogrammetric digital elevation model accuracy. Photogramm. Eng. Remote Sensing, 72, 771-779.

Warmerdam F., 2008. The Geospatial Data Abstraction Library. In: Hall G.B., Leahy M.G. (eds) Open Source Approaches in Spatial Data Handling. Advances in Geographic Information Science, vol 2. Springer, Berlin, Heidelberg. 